ANALYTICAL CHALLENGE

\section{Trifluoroacetic acid NMR challenge}

\author{
Marie-Pier Thibeault ${ }^{1} \cdot$ Juris Meija ${ }^{1}$ \\ Published online: 4 January 2021 \\ (C) Crown copyright in right of Canada 2020
}

We would like to invite you to participate in the Analytical Challenge, a series of puzzles to entertain and challenge our readers. This special feature of "Analytical and Bioanalytical Chemistry" has established itself as a truly unique quiz series, with a new scientific puzzle published every three months. Readers can access the complete collection of published problems with their solutions on the ABC homepage at http://www.springer.com/abc. Test your knowledge and tease your wits in diverse areas of analytical and bioanalytical chemistry by viewing this collection.

In the present challenge, NMR spectra is the topic. And please note that there is a prize to be won (a Springer book of your choice up to a value of $€ 100$ ). Please read on...

\section{Meet the challenge}

Nuclear magnetic resonance (NMR) is a powerful technique to study molecular structure. NMR spectra can be accurately predicted using quantum chemical calculations; interpreting the NMR spectra is a skill that remains a staple in analytical and organic chemistry curriculum. While simple compounds often have simple NMR spectra, the presence of isotopes complicates the NMR spectra and adds another layer of complexity that is often overlooked. Consider one of the simplest alkanes - ethane. Despite popular intuition, the ${ }^{1} \mathrm{H}-\mathrm{NMR}$ spectrum of natural ethane does not have a single signal. Rather, the textbook "single peak spectrum" is significantly more complex due to interactions that occur between the naturally occurring carbon13 isotopes. In ${ }^{13} \mathrm{CH}_{3}{ }^{12} \mathrm{CH}_{3}$, which accounts for $2 \%$ of all naturally occurring ethane molecules, there are interactions between ${ }^{1} \mathrm{H}$ and ${ }^{13} \mathrm{C}\left({ }^{1} J_{\mathrm{HC}}\right.$ and $\left.{ }^{2} J_{\mathrm{HC}}\right)$ and between the protons across the molecule $\left({ }^{3} J_{\mathrm{HH}}\right)$. In addition, ethane also contains small amounts of doubly labeled ${ }^{13} \mathrm{CH}_{3}{ }^{13} \mathrm{CH}_{3}$ isotopologue with even more complex networks of interactions between carbon- 13 atoms and protons. Given the importance of isotopically labeled compounds in modern chemistry, it is therefore of value to appreciate the added layer of complexity that isotopic labeling imparts on the NMR spectra of simple substances.

\section{The challenge}

Trifluoroacetic acid $\left(\mathrm{CF}_{3} \mathrm{COOH}, \mathrm{TFA}\right)$ is often used as an ion pairing agent in liquid chromatography to separate peptides and small proteins. Like with the ${ }^{1} \mathrm{H}-\mathrm{NMR}$ spectrum of ethane, the "textbook" description of its ${ }^{19} \mathrm{~F}-\mathrm{NMR}$ spectrum consists of a single peak near $76 \mathrm{ppm}$ relative to $\mathrm{CFCl}_{3}$. This challenge invites you to consider the TFA wherein both carbon atoms are carbon-13.

Which of the spectra shown in Fig. 1 most closely resembles the ${ }^{19}$ F-NMR spectrum of TFA with doubly labeled carbon-13 present?

Juris Meija

juris.meija@nrc-cnrc.gc.ca

1 National Research Council Canada, Ottawa, Canada 

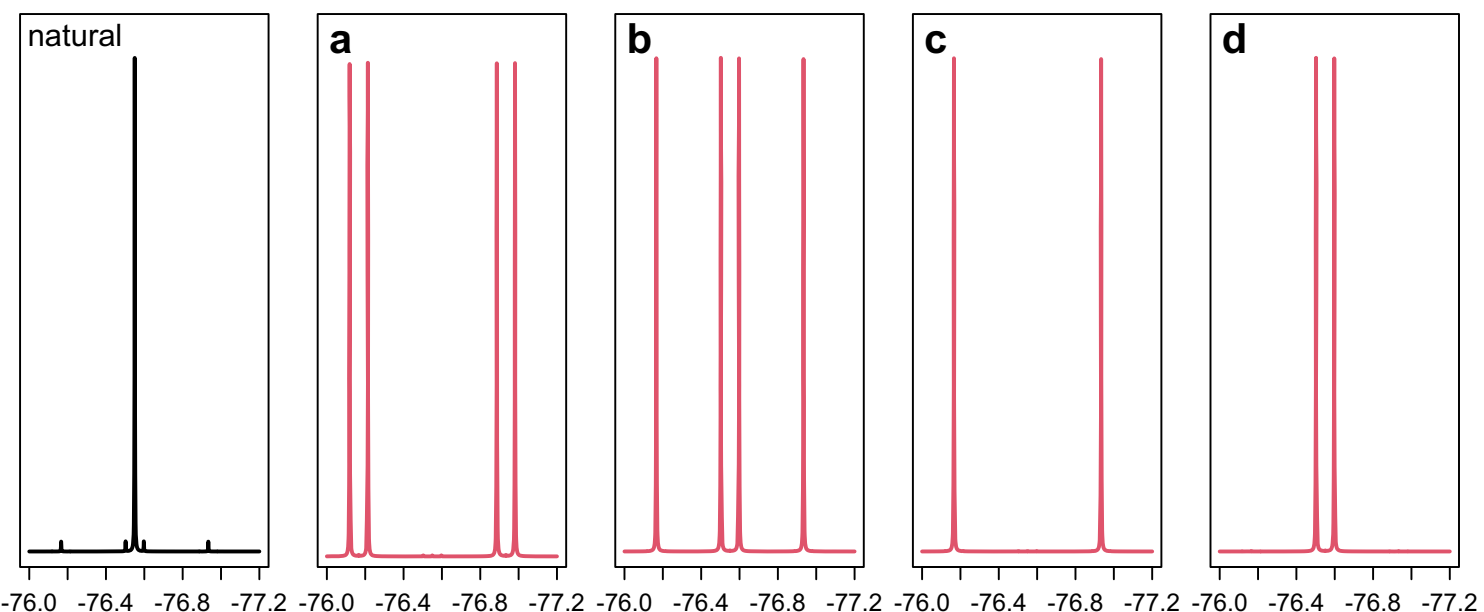

Fig. 1 Panel to the left shows the ${ }^{19} \mathrm{~F}-\mathrm{NMR}$ spectrum $(400 \mathrm{MHz})$ of trifluoroacetic acid having natural isotopic composition of all elements. Which of the other four spectra (panels a-d) most closely resembles the ${ }^{19} \mathrm{~F}-\mathrm{NMR}$ spectrum of a doubly labeled $\left[{ }^{13} \mathrm{C}_{2}\right]$-TFA?

We invite our readers to participate in the Analytical Challenge by solving the puzzle above. Please send the correct solution to abc-challenge@springer.com by April 1,2021. Make sure you enter "Trifluoroacetic acid NMR challenge" in the subject line of your e-mail. The winner will be notified by email and their name will be published on the "Analytical and Bioanalytical Chemistry" homepage at http://www.springer. com/abc and in the journal (volume 413/issue 17) where readers will find the solution and a short explanation.
The next Analytical Challenge will be published in 413/9, April 2021. If you have enjoyed solving this Analytical Challenge, you are invited to try the previous puzzles on the ABC homepage.

Publisher's note Springer Nature remains neutral with regard to jurisdictional claims in published maps and institutional affiliations. 